\title{
БРЕКЗИТ КАК ПРОЦЕСС
}

\begin{abstract}
Аннотация. 29 марта 2019 г. Британия не вышла из Европейского союза. На саммите Евросоюза 10 апреля Соединённому Королевству предоставили уже вторую отсрочку брекзита - до 31 октября 2019 г., обусловив её проведением в Британии выборов в Европейский парламент. На выборах могут потерпеть поражение консерваторы. Правительству необходимо получить одобрение сделки с Брюсселем до 22 мая, чтобы не проводить выборы.
\end{abstract}

Ключевые слова: брекзит, Тереза Мэй, британский парламент, Европейский союз, Лейбористская партия, Консервативная партия, Европейский парламент.

Брекзит (выход Британии из Европейского союза) должен был состояться 29 марта 2019 г. Однако из единовременного акта он превратился в процесс: британский парламент трижды отказался одобрить Соглашение с ЕC, а последний предоставил Лондону уже две отсрочки выхода.

\section{Патовая ситуация в парламенте}

После второго провала Соглашения с ЕС в британском парламенте 15 января 2019 г. была определена очерёдность голосования в связи с брекзитом ${ }^{1}$ :

1. по дополненному Соглашению с ЕС (12 марта)

если соглашение будет отклонено, то

2. по выходу без сделки (No-deal) (13 марта)

если выход без сделки будет отклонен, то

3. по отсрочке выхода из ЕС (14 марта)

12 марта 2019 г. в Вестминстере состоялось голосование по Соглашению с Евросоюзом с дополнениями по итогам переговоров Т. Мэй с председателем Европейской комиссии Ж.К. Юнкером². Изменения касались основополагающих вопросов, которые волновали брекзитёров из партии тори: будет ли ограничен срок временного пребывания Британии в Таможенном союзе ЕС и сможет ли Британия выйти из Таможенного союза с ЕС в одностороннем порядке, если так и не будет решена проблема режима границы между Северной Ирландией и Республикой Ирландия. По Соглашению от 25 ноября 2018 г. $^{3}$, такой вариант был исключён, что не устраивало брекзитёров.

(C) Ананьева Елена Владимировна - кандидат философских наук, ведущий научный сотрудник, руководитель Центра британских исследований ИЕ РАН. Адрес: 125009, Россия, Москва, ул. Моховая, д. 11, стр. 3. E-mail: e-ananieva@yandex.ru.

DOI: http://dx.doi.org/10.15211/vestnikieran220192632

${ }^{1}$ HC. Wednesday 27 February 2019. Votes and Proceedings. P. 4.

2 «Instrument relating to the agreement on the withdrawal of the United Kingdom of Great Britain and Northern Ireland from the European Union and the European Atomic Energy Community». 11 March 2019.

${ }^{3}$ Agreement on the withdrawal of the United Kingdom of Great Britain and Northern Ireland from the European Union and the European Atomic Energy Community, as endorsed by leaders at a special meeting of the European Council on 25 November 2018. Withdrawal Agreement and Political Declaration; Political Declaration Setting Out the Framework for the Future Relationship Between the European Union and the United Kingdom. 
Решающим фактором стало заключение генерального прокурора Дж. Кокса по дополненному соглашению: «правовые риски остаются неизменными», поскольку Британия не сможет в одностороннем порядке отказаться от своих обязательств ${ }^{1}$. После заключения Дж. Кокса неизвестно было лишь одно - «с каким счётом» Т. Мэй вновь проиграет (первый раз большинством в 230 голосов ${ }^{2}$ ). 12 марта 2019 г. Палата общин отвергла дополненное соглашение 391:242 3 (второй раз большинством в 149 голосов, из них 75 консерваторов). Т. Мэй потерпела уже восемнадцатое поражение в парламенте, четвёртое самое крупное за его историю.

Если член правительства голосует против его курса, то обязан уйти в отставку или его снимают с должности. Однако внутрипартийные разногласия столь остры, что и среди консерваторов и лейбористов часть парламентариев нарушает предписания «кнутов».

13 марта Т. Мэй снова потерпела поражение. Для понимания метаморфоз брекзита поясним: правительство внесло проект резолюции, согласно которому отвергался выход из ЕС без сделки, намеченный именно на 29 марта (но не в других случаях) ${ }^{4}$, на этот раз предоставив депутатам-тори свободу голосования.

Спикер Дж. Беркоу к проекту резолюции правительства сначала поставил на голосование две поправки ${ }^{5}$ Поправку Грина («компромисс Молтхауса») ${ }^{6}$ парламент отклонил ${ }^{7}$. Что касается поправки Спелман, то напомним: ещё 29 января 2019 г. парламент одобрил межпартийную поправку Кэролайн Спелман (тори) и Дж. Дроми (лейборист) против выхода Британии из ЕС «без Соглашения о выходе и Политической декларации ${ }^{8}$. Особенность поправки 13 марта состояла в том, что она налагала запрет на выход без сделки вообще, а не только 29 марта.

Парламент одобрил поправку Спелман незначительным большинством 312:3089 . Партийные организаторы - «кнуты» обязали консерваторов голосовать против поправки, но 9 депутатов поддержали её. Тогда руководство партии дало указание «кнутам» обеспечить голоса депутатов-тори против проекта правительства, и сама Т. Мэй голосовала против собственного проекта резолюции. Однако было уже поздно: резолюция правительства прошла с поправкой Спелман $(321: 278)^{10} .17$ консерваторов-бремейнеров поддержали резолюцию, а 13 членов правительства воздержались!

Одобрение поправки Спелман означает, что законодательная власть перехватывает полномочия у исполнительной. Более того, обычно были бы неминуемы увольнения членов правительства, которые нарушили жёсткие указания «кнутов», но Т. Мэй решила не отправлять их в отставку. Таким образом, премьер-министр окончательно утратила контроль не только над парламентом, партийной фракцией, но и правительством, поскольку коллективная ответ-

${ }^{1}$ Legal Opinion on Joint Instrument and Unilateral Declaration concerning the Withdrawal Agreement. Published 12.03.2019.

${ }_{3}^{2}$ HC. Tuesday 15 January 2019. Votes and Proceedings. P. 2.

3 Government's Brexit deal defeated again in «meaningful vote». URL: https://www.parliament.uk/business/news/ 2019/march/key-brexit-vote-as-meaningful-vote-returns-to-the-commons/

${ }^{4}$ House of Commons to vote on no-deal Brexit. URL: https://www.parliament.uk/business/news/2019/march/house-ofcommons-to-vote-on-no-deal-brexit/

5 Выбор поправок для голосования - прерогатива спикера палаты. Брекзитёры обвиняют Дж. Беркоу в потворстве бремейнерам и выступают за его отставку.

${ }^{6}$ Елена Ананьева. Сработает ли «компромисс Молтхауса»? URL: https://interaffairs.ru/news/show/21549.

${ }^{7}$ HC. Wednesday 13 March 2019. Votes and Proceedings. P. 3. Её в основном поддержали брекзитёры и некоторые бремейнеры, поскольку она предусматривала «упорядоченный» выход без сделки (managed no deal) с отсрочкой выхода до 22 мая (до выборов в Европарламент, чтобы Британия в них не участвовала), продлением переходного периода до конца 2021 г. и взносах Британии в бюджет ЕС.

Елена Ананьева. Сработает ли «компромисс Молтхауса»? 01.02.2019. URL: https://interaffairs.ru/news/ show/21549.

${ }_{9}^{10}$ HC. Wednesday 13 March 2019. Votes and Proceedings. P. 2.

${ }^{10}$ Ibid. P. 3.

Научно-аналитический вестник ИЕ РАН, 2019, №2 
ственность Кабинета, что предписано конституционными установлениями, совершенно распалась. К тому же и рядовых депутатов-тори впредь нельзя будет заставить придерживаться партийной дисциплины.

Поправка не имела обязательного характера: резолюция парламента не может отменить закон. По закону Британия выйдет из Евросоюза без сделки, если не будет договорено иное. Таким образом, вариант выхода без сделки остаётся, если страны - члены ЕС откажутся предоставить Британии очередную отсрочку (что не во власти парламента) или парламент всё же одобрит сделку.

14 марта парламент голосовал по проекту резолюции правительства об отсрочке выхода из ЕС (412:202) ${ }^{1}$ с возможностью третьего «решающего» голосования по соглашению. В Брюсселе заявили, что Британия должна представить веские основания для отсрочки, и существует лишь два способа выйти из Европейского союза - со сделкой или без сделки. Проголосовать против выхода без сделки недостаточно. Главный переговорщик от ЕС М. Барнье заявил, что отсрочку Британии предоставят в случае досрочных выборов или повторного референдума, а переговоры закончились ${ }^{2}$.

\section{Саммит ЕС 21 марта - первая отсрочка. Третье голосование по соглашению с ЕС}

Главы 27 стран - членов ЕС на своём саммите предоставили Британии отсрочку выхода лишь до 22 мая 2019 г., поскольку 23 мая начинаются выборы в Европарламент, в которых Британия уже участвовать не должна была бы. Условие - одобрение британским парламентом Соглашения с Евросоюзом. В противном случае Британия должна участвовать в выборах в Европейский парламент. Иначе - выход без сделки ${ }^{3}$.

Сославшись на прецедент 1604 г., спикер парламента постановил, что правительство не имеет права ставить на голосование один и тот же документ без существенных изменений в течение одной сессии парламента (чтобы правительство не брало депутатов «на измор»).

В результате 27 марта в Вестминстере снова разыгрались драмы. Тереза Мэй обещала фракции своей партии уйти в отставку в обмен на поддержку при возможном третьем голосовании по Соглашению с ЕС. Суть предложений премьер-министра - всё же провести брекзит, создать хотя бы видимость единства Консервативной партии, сохранить правительство тори у руля страны и не допустить Дж. Корбина к власти; а новый лидер тори будет вести переговоры с ЕС на следующей их фазе.

Даже стойкие брекзитёры (Б. Джонсон и Дж. Рис-Могг) готовы были отдать свой голос за Соглашение с Европейским союзом. Первый хотел бы выставить свою кандидатуру в лидеры партии. Второй решил, что лучше «плохая сделка, чем членство в ЕС» и что брекзит - «не одноразовый акт, а процесс» ${ }^{4}$. Их расчёт заключался в том, чтобы обеспечить брекзит в любой форме и добиться уступок на переговорах о будущих отношениях Британии с Евросоюзом.

Тогда же прошло «индикативное голосование» по вариантам действий. Ни один не набрал большинство: депутаты проголосовали против второго референдума, против таможенного союза, против выхода без сделки - в один день. Результаты свидетельствуют о глубочайшей фрагментации парламента.

Британская общественность не остаётся в стороне. 23 марта в Лондоне состоялась де-

\footnotetext{
${ }_{1}^{1}$ HC. Thursday 14 March 2019. Votes and Proceedings. P. 3.

2 Барнье: «Главное не “развод”, а будущие отношения с Великобританией». 13.03.2019. URL: https://ru.euronews. com/2019/03/13/michel-barnier-speaks-about-brexit.

${ }^{3}$ European Council (Art. 50) conclusions, 21 March 2019.

4 The Moggcast: Episode Twenty Six, Tuesday $26^{\text {th }}$ March 2019 URL: https://www.conservativehome.com/podcast/themoggcast-episode-twenty-six-tuesday-26th-march-2019.
}

Научно-аналитический вестник ИЕ РАН, 2019, №2 
монстрация за «народное голосование» (People's Vote), собравшая сотни тысяч людей. Петиция от 20 марта за отзыв уведомления по ст. 50 уже к 28 марта набрала почти 6 млн подписей. Правительство заявило, что отзывать уведомление по ст. 50 не станет, учитывая итоги референдума 2016 г. ${ }^{1}$

Т. Мэй, идя в обход спикера, решила отделить голосование по Соглашению (юридически обязывающему) от Политической декларации (не имеет юридической силы). Цель - оказать давление на Лейбористскую партию (ЛПВ) и Демократическую юнионистскую партию (ДЮП), поскольку обе вынуждены будут голосовать против Соглашения. Тем самым можно было бы возложить на них вину за выход без сделки или за длительную отсрочку брекзита.

Спикер Дж. Беркоу не сразу, но согласился поставить на голосование Соглашение с ЕС отдельно от Политической декларации (существенные изменения ведь не внесены). Ольстерские юнионисты заявили, что не поддержат сделку, поскольку сохраняется «стратегический риск» того, что таможенная граница по Ирландскому морю отрежет регион от остальной территории страны ${ }^{2}$. Лидер ДЮП Арлин Фостер отметила: для брекзитёров важнее брекзит, а для ДЮП - целостность королевства, единые условия для всей страны, и по вопросу, затрагивающему целостность страны, они воздержаться не могут ${ }^{3}$.

Отметим, что ЛПВ изначально возражала не столько против Соглашения с Евросоюзом (таможенный союз), сколько против Политической декларации, хотя считает их нераздельными. Обещание Т. Мэй уйти в отставку при одобрении парламентом Соглашения (без Политической декларации) лишь отвратило лейбористов. Опасаясь, что будущие отношения Британии с ЕС лишатся какой-либо ясности (тем более что новым лидером тори может стать брекзитёр), партия считала, что Т. Мэй предложила голосовать 29 марта за «самый слепой из всех слепых брекзитов», причём незаконно ${ }^{4}$.

Голосование 29 марта проходило на фоне крупной демонстрации у парламента, но уже сторонников брекзита. Итог голосования: Соглашение провалено $(286: 344)^{5} 58$ голосами (из них 34 тори).

Таким образом, 15 января 2019 г. депутаты отвергли Соглашение и Политическую декларацию, 12 марта - дополненное Соглашение и Политическую декларацию, 29 марта - дополненное Соглашение без Политической декларации. Британии предстояло либо выйти без сделки, либо к 12 апреля запрашивать у Брюсселя длительную отсрочку и участвовать в выборах в Европарламент.

\section{Саммит ЕС 10 апреля 2019 г. - вторая отсрочка. Евровыборы}

10 апреля на саммите Евросоюз предоставил Британии уже вторую отсрочку брекзита до 31 октября, тем самым отвратив её выход без сделки 12 апреля6. Заголовки европейских

\footnotetext{
${ }^{1}$ Petition. Revoke Article 50 and remain in the EU.

2 DUP Statement. 27 March 2019 URL: http://www.mydup.com/news/article/dup-statement1.

3 «The most important thing is the Union»-DUP won't support May's Brexit deal. 27.03.2019. URL: https://www.rte. $\mathrm{ie} / \mathrm{news} /$; Brexit: May clings on to hope of third vote for her deal this week. URL: https://www.theguardian.com/poli tics/2019/mar/26/jacob-rees-mogg-choice-likely-to-be-mays-deal-or-no-brexit. Не согласилась ДЮП и на предложение премьер-министра ввести «замо́к Стормонта» (решение парламента Северной Ирландии ${ }^{3}$ ) - механизм, который бы обеспечил единообразие законодательства региона и королевства в случае «бэкстопа», поскольку международный договор будет иметь приоритет над внутренним законодательством.

4 Теневой министр по выходу из ЕС К. Стармер. Labour says May’s resignation announcement makes backing her «blindfold Brexit» even harder. URL: https://www.theguardian.com/politics/blog/live/2019/mar/28/brexit-latest-newslive-no-deal-on-12-april-most-likely-unless-mps-back-mays-deal-or-alternative-says-letwin-politics-live?page=with: block-5c9cce93e4b0b4d18bde1c8f\#block-5c9cce93e4b0b4d18bde1c8f; Labour: «Four reasons why you can't split Brexit deal». 28.03.2019. URL: https://www.bbc.com/news/live/uk-politics-parliaments-47696409.

${ }_{6}^{5}$ HC. Friday 29 March 2019. Votes and proceedings. P. 2.

${ }^{6}$ Символично, что новая дата приходится на день Всех Святых (Хэллоуин - день поминовения всех умерших).
} Научно-аналитический вестник ИЕ РАН, 2019, №2 
газет были безжалостны: «Брекзит-ужастик», «Хэллоун-брекзит», «Англо-саксонский шабаш ведьм и тыкв» ${ }^{1}$. Конечно, в Брюсселе руководствовались не Хэллоуином, а вновь прагматическим соображениями обеспечить нормальное функционирование институтов Европейского союза.

На этом саммите среди государств - членов ЕС возникли разногласия. Ж-К. Юнкер обвинил президента Франции Э. Макрона в разрушении единства Евросоюза, поскольку последний не соглашался предоставить Британии длительную отсрочку (до 31 марта 2020 г.). Франция была даже готова к выходу Британии без сделки, лишь бы та не вмешивалась в процесс принятия решений и не импортировала свой политический кризис в ЕС: дисфункциональный ЕС хуже выхода Британии без сделки. Итоги саммита:

- соглашение не подлежит пересмотру;

- Британию обязали принять участие в выборах в Европейский парламент (23-26 мая 2019 г.) в качестве одной из гарантий отсрочки. В противном случае она должна будет выйти из ЕС к 1 июля 2019 г. (начало работы нового состава Европарламента);

- Британия сохраняет все права и обязательства члена Евросоюза;

- Британия вправе отозвать уведомление о выходе из $\mathrm{EC}^{2}$.

21 июня ЕС снова проведёт саммит, на котором будет сделан обзор состояния дел с брекзитом.

Сама Т. Мэй намерена вновь добиваться одобрения Соглашения, чтобы Британия вышла из ЕС до выборов в Европарламент, которые грозят партии тори сокрушительным поражением.

Каковы же варианты? Переговоры премьер-министра Т. Мэй с лидером оппозиции Дж. Корбином продолжатся, но вряд ли закончатся успешно, поскольку компромисс в каждой из партий расценят как непозволительную уступку. Лейбористам нет смысла выручать консерваторов из кризиса, а консерваторы могут действительно расколоться в случае уступок «леваку» Дж. Корбину. Голосование по компромиссному решению не принесёт успех. Все возможные варианты, кроме запрета на выход без сделки, парламент уже провалил.

Вряд ли изменит ситуацию и смена лидера тори. Напомним, что Т. Мэй выиграла вотум доверия и может оставаться на своём посту до 12 декабря 2019 г. Однако низовое звено партии намерено правила изменить на Чрезвычайном общем собрании 3 .

Отсрочка, которую предоставил Евросоюз, слишком коротка, чтобы провести новый референдум, но достаточна для новых досрочных всеобщих выборов. Однако новый состав парламента может оказаться, как и сейчас - «подвешенным», пусть и при преимуществе лейбористов.

В Брюсселе опасаются, что Британия может устроить обструкцию при назначении нового председателя Еврокомиссии и Председателя Совета ЕС, хотя их утверждают квалифицированным большинством. Брекзитёры уже пообещали, что в новом составе Европарламента они не позволят увеличить бюджет Европейского союза, создать европейскую армию, развалят планы Э. Макрона по федерализации ЕС.

Выборы в Европарламент, а также местные выборы в Британии (2 мая 2019 г.) станут

\footnotetext{
1 «It's a Halloween Brexit»: European media's verdict on latest delay. URL: https://www.theguardian.com/politics/ 2019/apr/11/its-a-halloween-brexit-european-media-give-their-verdict.

${ }_{3}^{2}$ Special meeting of the European Council (Art. 50) (10 April 2019)-Conclusions.

3 MPs hatch plan to OUST Theresa May with ANOTHER no confidence vote «within WEEKS». URL: https://www.express.co.uk/news/politics/1115222/brexit-news-latest-theresa-may-no-confidence-vote-tory-leadershipleave-EU. 17.04.2019.
}

Научно-аналитический вестник ИЕ РАН, 2019, №2 
суррогатным вторым референдумом об отношениях с $\mathrm{EC}^{1}$. Размежевание по отношению к брекзиту приобретает устойчивость ${ }^{2}$, а потому и всеобщие парламентские выборы могут вновь закончиться «подвешенным парламентом», а второй референдум - столь же шатким большинством. Независимо от исхода брекзита латентная гражданская война в Британии продолжится. Не существует варианта, который бы устроил все стороны, а потому вину за любые последствия они будут возлагать друг на друга ещё годы.

\section{Выводы}

1. В парламенте сохраняется патовая ситуация; законодательная власть перехватывает полномочия у исполнительной.

2. Премьер-министр утратила контроль над парламентской фракцией и над правительством.

3. Переговоры правительства с оппозицией не могут принести успех.

4. Низовое звено партии тори стремится изменить устав партии, чтобы добиться смещения лидера.

5. В свете выборов в Европейский парламент бремейнеры добиваются второго референдума, а брекзитёры - выхода без сделки и могут одержать на них победу.

6. Соответственно, правительство будет добиваться ещё одного голосования по соглашению с Европейским союзом (до 22 мая 2019 г.), чтобы в Британии не состоялись выборы в Европарламент.

\section{Список литературы}

Ананьева Е.В. Состоятся ли в Британии выборы в Европейский парламент? Аналитическая записка №9(160), 2019. URL: http://www.instituteofeurope.ru/images/uploads/analitika/ 2019/an160.pdf.

\section{References}

Anan'eva E.V. Sostojatsja li v Britanii vybory v Evropejskij parlament? Analiticheskaja zapiska №9(160), 2019. URL: http://www.instituteofeurope.ru/images/uploads/analitika/ 2019/an160.pdf.

Agreement on the withdrawal of the United Kingdom of Great Britain and Northern Ireland from the European Union and the European Atomic Energy Community, as endorsed by leaders at a special meeting of the European Council on 25 November 2018. Withdrawal Agreement and Political Declaration; Political Declaration Setting Out the Framework for the Future Relationship between the European Union and the United Kingdom.

DUP Statement. 27 March 2019. URL: http://www.mydup.com/news/article/dup-statement1.

European Council (Art. 50) conclusions, 21 March 2019.

Government's Brexit deal defeated again in «meaningful vote». URL: https://www.parliament. uk/business/news/2019/march/key-brexit-vote-as-meaningful-vote-returns-to-the-commons/

House of Commons. Votes and Proceedings. 2019.

\footnotetext{
${ }^{1}$ Ананьева Е.В. Состоятся ли в Британии выборы в Европейский парламент? Аналитическая записка №9(160), 2019. URL: http://www.instituteofeurope.ru/images/uploads/analitika/2019/an160.pdf.

${ }^{2}$ По опросу, в качестве следующего лидера партии рядовые консерваторы хотели бы видеть Б. Джонсона (19\%). Вслед за ним идёт Н. Фарадж (15\%, если бы был членом партии). За его партию на евровыборах готовы голосовать 40\% депутатов местных органов власти из числа тори. Nigel Farage voted second-favourite CONSERVATIVE LEADER by Tory councilors. URL: https://www.express.co.uk/news/politics/1117110/brexit-latest-nigel-farage-thebrexit-party-poll-boris-johnson-tory-leadership-bid. 21.04.2019.
}

Научно-аналитический вестник ИЕ РАН, 2019, №2 
House of Commons to vote on no-deal Brexit. URL: https:/www.parliament.uk/business/ news/2019/march/house-of-commons-to-vote-on-no-deal-brexit/

Instrument relating to the agreement on the withdrawal of the United Kingdom of Great Britain and Northern Ireland from the European Union and the European Atomic Energy Community. 11 March 2019.

Legal Opinion on Joint Instrument and Unilateral Declaration concerning the Withdrawal Agreement. Published 12.03.2019. URL: https://www.gov.uk/government/publications/legal-opinionon-joint-instrument-and-unilateral-declaration-concerning-the-withdrawal-agreement.

Special meeting of the European Council (Art. 50) (10 April 2019) - Conclusions.

\section{Brexit As a Process}

Author. Elena Ananieva, Candidate of Sciences (Philosophy), Head of Centre for UK Studies, Institute of Europe, Russian Academy of Sciences. Address: 11-3, Mokhovaya str., Moscow, Russia, 125009. E-mail: e-ananieva@yandex.ru.

Abstract. The UK did not leave the EU on March 29, 2019. The EU granted Britain a second delay until 31 October 2019 under the condition of holding elections to the European Parliament. Since the Tory party might suffer a heavy defeat the government will try to push the Brexit deal through parliament before 22 May to avoid EU elections.

Key words: Brexit, Theresa May, UK parliament, European Union, Labour Party, Conservative Party, political crisis, European Parliament.

DOI: http://dx.doi.org/10.15211/vestnikieran220192632 